\title{
Sự biến đổi của ngày bắt đầu mùa mưa ở Tây nguyên và khả năng dự báo
}

\author{
Phan Văn Tân ${ }^{1, *}$, Phạm Thanh Hà ${ }^{1}$, Nguyễn Đăng Quang ${ }^{2}$, \\ Nguyễn Văn Hiệp ${ }^{3}$, Ngô Đức Thành ${ }^{4}$ \\ ${ }^{1}$ Trường Đại học Khoa học Tự nhiên, ĐHQGHN, 334 Nguyễn Trãi. Hà Nội, Việt Nam \\ ${ }^{2}$ Trung tâm Khi tượng Thuỷ văn Quốc gia \\ ${ }^{3}$ Viện Vật lý Địa cầu, Viện Hàn lâm Khoa học và Công nghệ Việt Nam \\ ${ }^{4}$ Truờng Đại học Khoa học và Công nghệ Hà Nội, Viện Hàn lâm Khoa học và Công nghệ Việt Nam
}

Nhận ngày 08 tháng 8 năm 2016

Chỉnh sửa ngày 26 tháng 8 năm 2016; Chấp nhận đăng ngày 16 tháng 12 năm 2016

\begin{abstract}
Tóm tắt: Trong nghiên cứu này, sử dụng số liệu quan trắc lượng mưa ngày trên các trạm khí tượng khu vực Tây Nguyên giai đoạn 1981-2010, một vài đặc điểm chế độ mưa bao gồm ngày bắt đầu mùa mưa và sự biến đổi cũng như khả năng dự báo ngày bắt đầu mùa mưa đã được khảo sát. Kết quả nhận được cho thấy: 1) Ngày bắt đầu mùa mưa ở Tây Nguyên biến thiên mạnh qua các năm. Mùa mưa bắt đầu sớm hơn ở phía nam Tây Nguyên sau đó là phía bắc và muộn nhất ở miền trung. Nhìn chung, mùa mưa ở Tây Nguyên bắt đầu vào khoảng giữa tháng 4 đến giữa tháng 5 , trung bình vào khoảng 30 tháng 4 hàng năm; 2) Mùa mưa ở Tây Nguyên có xu thế đến sớm hơn 5-7 ngày/thập kỷ; 3) Ngày bắt đầu mùa mưa ở Tây Nguyên có tương quan dương cao với nhiệt độ bề mặt biển (SST) ở khu vực trung tâm Thái Bình dương xích đạo và nam Ấn Độ dương xích đạo, gió vĩ hướng mực $850 \mathrm{hPa}$ khu vực tây bắc và trung tâm Thái Bình dương xích đạo và với khí áp mực biển trung bình trên các khu vực tây Thái Bình dương và Ân Độ dương, có tương quan âm với SST trên khu vực tây Thái Bình dương xích đạo, gió vĩ hướng mực $850 \mathrm{hPa}$ trên vùng biển Ân Độ dương xích đạo. Ngoài ra, bằng phương pháp phân tích thành phần chính đối với các trường SST, gió vĩ hướng trên mực $850 \mathrm{hPa}$ và khí áp mực biển trung bình trên một số vùng được lựa chọn để xác định các nhân tố dự báo; phương trình dự báo ngày bắt đầu mùa mưa trên Tây Nguyên cũng đã được xây dựng bằng phương pháp hồi qui từng bước. Kết quả chỉ ra rằng, sai số trung bình dự báo của phương pháp là 0,2 ngày và sai số tuyệt đối là 6 ngày.
\end{abstract}

Tư khoá: Ngày bắt đầu mùa mưa, Dự báo mưa, Tây Nguyên, Việt Nam.

\section{Mở đầu}

Đặc điểm phân bố không gian, thời gian và sự biển đổi của các đặc trưng mưa như tổng lượng mưa tháng và năm, biến trình năm, ngày bắt đầu và kết thúc mùa mưa,... có vai trò đặc

*Tác giả liên hệ. ĐT.: 84-4-35583811

Email: phanvantan@hus.edu.vn biệt quan trọng trong nhiều lĩnh vực như sản xuất nông nghiệp, quản lý tài nguyên nước, vận hành và điều tiết hồ chứa nước thuỷ lợi, thuỷ điện,... Cho đến nay đã có nhiều công trình nghiên cứu về mưa ở Việt Nam cũng như các nước xung quanh (Matsumoto, 1997; Ngo-Duc và $C S$, 2013; Nguyen-Le và CS, 2015a,b; Nguyen-Thi và CS, 2012; Yen và $C S, 2011$ 
[1-6]). Về cơ bản biến trình mưa hàng năm ở Việt Nam có hai dạng: Ở các vùng khí hậu phía bắc, một phần Bắc Trung Bộ, Nam Bộ và Tây Nguyên mùa mưa trùng với mùa gió mùa mùa hè (tháng 5 đến tháng 10), trong khi ở Nam Trung Bộ và phần còn lại của Bắc Trung Bộ mùa mưa dịch chuyển về các tháng cuối mùa hè và đầu mùa đông (tháng 8 đến tháng 12) (Nguyễn Đức Ngữ và CS, 2013 [7]). Tuy vậy, trong số các vùng khí hậu Việt Nam, Tây Nguyên và Nam Bộ là những vùng có chế độ mưa điển hình của gió mùa Nam Á với hai mùa tương phản rõ rệt là mùa khô và mùa mưa, trong đó thời điểm chuyển dịch từ mùa khô sang mùa mưa được đặc trưng bởi sự tăng lên đột ngột của lượng mưa trong khoảng thời gian từ cuối tháng 4 đến giữa tháng 5 (Zhang và $C S$, 2002 [8]). Thời điểm đó được gọi là ngày bắt đầu mùa mưa (Onset Rainy season Date ORD). Quá trình chuyển từ mùa khô sang mùa mưa hay ORD có liên hệ chặt chẽ với sự bùng nổ gió mùa mùa hè châu Á. Đây là thời điểm hết sức quan trọng, đặc biệt đối với khu vực Tây Nguyên, vì nó đánh dấu sự chấm dứt một thời kỳ khô hạn kéo dài trong năm và bắt đầu thời kỳ sinh trưởng và phát triển của các loại cây công nghiệp như cà phê, hồ tiêu,... những đặc sản xuất khẩu nổi tiếng của Việt Nam. Chính vì vậy, việc nghiên cứu dự báo ORD là một trong những chủ đề rất được quan tâm bởi tầm quan trọng và ý nghĩa thực tiễn của nó.

ORD thường được xác định thông qua các chỉ tiêu liên quan tới lượng mưa (Laux và $\mathrm{CS}$, 2008 [9]). Các chỉ tiêu này là khác nhau đối với từng khu vực cụ thể. Matsumoto (1997) [1] đã xác định ORD trên khu vực bán đảo Đông Dương dựa trên số liệu mưa trung bình 5 ngày giai đoạn 1975-1987 và cho thấy, ORD rơi vào khoảng cuối tháng 4 đầu tháng 5 , sớm hơn so với khu vực duyên hải vịnh Bengal. Trong khi đó Wang và LinHo (2002) [10] đã xác định ORD trên khu vực Châu Á - Thái Bình Dương khi sử dụng độ lệch giữa lượng mưa pentad (5 ngày) với lượng mưa của mùa đông tương ứng. Kết quả chỉ ra rằng $\mathrm{ORD}$ trên khu vực đông nam vịnh Bengal vào khoảng cuối tháng 4 (pentad 23-24), sau đó là bán đảo Đông Dương, khoảng đầu tháng 5 (pentad 25-26), và tiếp đến là khu vực Biển Đông, khoảng giữa tháng 5 (pentad 27-28). Do thời kì bùng nổ gió mùa mùa hè có mối quan hệ chặt chẽ với giai đoạn chuyển giao từ mùa khô sang mùa mưa, nên ở một số khu vực ORD thường được xem là ngày bắt đầu gió mùa mùa hè. Với cách tiếp cận đó, dựa trên chuỗi số liệu mưa 46 năm (19511996), Zhang và CS (2002) [8] đã chỉ ra ngày bắt đầu gió mùa mùa hè Châu Á trên khu vực bán đảo Đông Dương trung bình vào ngày $9 / 5$ với độ lệch chuẩn 12 ngày.

Quan hệ giữa ngày bắt đầu gió mùa mùa hè với ENSO cũng đã được nhiều tác giả đề cập tới. Chẳng hạn, Lau và CS (1997) [11] đã tìm ra sự xuất hiện muộn hơn (sớm hơn) của gió mùa mùa hè trên khu vực Biền Đông có mối liên hệ với sự nóng lên (lạnh đi) ở Thái Bình Dương và Ấn Độ Dương. Zhou và CS (2007) [12] đã khảo sát mối liên hệ giữa ngày bắt đầu gió mùa Đông Nam Á (hay còn gọi là gió mùa Nam Hải, tức gió mùa Biển Đông) và ENSO khi sử dụng số liệu tái phân tích NCEP (Trung tâm dự báo môi trường Hoa Kỳ) và ECMWF (Trung tâm dự báo hạn vừa Châu Âu). Ngày bắt đầu gió mùa được xác định trên cơ sở gió vĩ hướng mực $850 \mathrm{mb}$ trên khu vực Biển Đông chuyển từ gió đông sang gió tây kéo dài liên tục 2 pentad. Kết quả nhận được chỉ ra rằng trong những năm thuộc pha nóng (lạnh) hoặc năm tiếp theo sự kiện ENSO gió mùa có xu hướng bắt đầu muộn hơn (sớm hơn) với cường độ yếu hơn (mạnh hơn). Nguyễn Thị Hiền Thuận và CS (2007) [13] lại cho thấy ngày bắt đầu mùa mưa ở Nam Bộ sẽ đến muộn hơn trong những năm $\mathrm{El}$ Niño và sớm hơn trong những năm La Niña. Khi nghiên cứu mối quan hệ giữa nhiệt độ bề mặt biển (SST) trên khu vực nhiệt đới Thái Bình Dương $(28 \mathrm{~N}-28 \mathrm{~S} ; 120 \mathrm{E}-85 \mathrm{~W})$ và Ấn Độ Dương $(28 \mathrm{~N}-$ $28 \mathrm{~S}$; 30E-105E) với lượng mưa tháng ở Tây Nguyên tác giả Nguyen (2007) [14] cũng đã chỉ ra sự thay đổi của SST có ảnh hưởng rõ rệt đến ngày bắt đầu và kết thúc gió mùa mùa hè.

Mặc dù tồn tại mối quan hệ chặt chẽ giữa $\mathrm{ORD}$ và ngày bắt đầu gió mùa mùa hè, nhưng do mưa là hệ quả của sự tương tác phức tạp giữa nhiều hệ thống thời tiết khác nhau đồng 
thời chịu ảnh hưởng mạnh mẽ của điều kiện địa phương, như địa hình, hướng sườn, hướng núi,... nên ngày bắt đầu mùa mưa có thể không cùng thời điểm với ngày bắt đầu mùa gió mùa mùa hè. Do tầm quan trọng của việc dự báo ngày bắt đầu mùa mưa nên gần đây đã có nhiều công trình nghiên cứu đề cập đến vấn đề này, chẳng hạn Laux (2008) [8], Moron (2008) [15]. Trong phạm vi bài báo này, một vài đặc điểm biến đồi của ngày bắt đầu mùa mưa cũng như khả năng dự báo nó cho khu vực Tây Nguyên sẽ được trình bày. Mục 2 của bài báo sẽ giới thiệu về phương pháp nghiên cứu và số liệu được sử dụng. Những kết quả nghiên cứu chính và thảo luận được trình bày trong mục 3 . Mục 4 là một số kết luận.

\section{Phương pháp và số liệu}

\subsection{Số liệu}

Số liệu được sử dụng trong nghiên cứu này bao gồm: 1) Số liệu quan trắc mưa ngày trên mạng lưới trạm khí tượng khu vực Tây Nguyên; 2) Sổ liệu tái phân tích của hệ thống dự báo khí hậu (CFS) của Trung tâm dự báo môi trường Hoa Kỳ (NCEP) độ phân giải 0.5 x 0.5 độ (CFSR0.5). Cả hai bộ số liệu này đều lấy trong giai đoạn 1981-2010 (30 năm).

Số liệu mưa ngày tại trạm được sử dụng để xác định ngày bắt đầu mùa mưa (ORD) cho khu vực Tây Nguyên. Trên thực tế có thể khai thác được tối đa 47 trạm quan trắc mưa ở Tây Nguyên, trong đó có 17 trạm khí tượng và 30 trạm đo mưa nhân dân (Phan và CS [16]). Tuy nhiên, để đảm bảo chất lượng, số liệu từ các trạm đo mưa nhân dân sẽ không được sử dụng. Trong số 17 trạm khí tượng còn lại, một số trạm có độ dài chuỗi số liệu quá ngắn, một số trạm số liệu bị gián đoạn nhiều, còn một số trạm khác có vị trí nằm hơi lệch hoặc thuộc sườn đông dãy Trường Sơn Nam, chịu ảnh hưởng của mùa mưa vùng Nam Trung Bộ, không phù hợp với mục đích nghiên cứu. Kế quả sau quá trình tiền xử lý đã chọn được 10 trạm có thể sử dụng số liệu (bảng 1).
Số liệu tái phân tích CFSR0.5 được cho trên các mặt đẳng áp chuẩn trên phạm vi toàn cầu. Cho mục đích của nghiên cứu này, các trường khí áp mực biển (PSML), thành phần gió vĩ hướng mực $850 \mathrm{mb}$ (U850) và nhiệt độ mặt nước biển (SST) giới hạn trong miền từ $40^{\circ} \mathrm{E}-$ $100^{\circ} \mathrm{W}$ và từ $40^{\circ} \mathrm{S}-40^{\circ} \mathrm{N}$ được sử dụng.

\subsection{Xác định ngày bắt đầu mùa mưa}

Ngày bắt đầu mùa mưa (ORD) là một khái niệm dùng để chỉ thời điểm trong năm mà từ đó mưa xảy ra thường xuyên hơn với lượng mưa đủ lớn và có thể kéo dài từng đợt sao cho tổng lượng mưa tháng phải lớn hơn hoặc bằng một ngưỡng nào đó, và phải kéo dài liên tục trong nhiều tháng. Ở Việt Nam, mùa mưa trong một năm nào đó được xem là các tháng liên tục có tổng lượng mưa tháng lớn hơn hoặc bằng $100 \mathrm{~mm} /$ tháng (Nguyễn Đức Ngữ và Nguyễn Trọng Hiệu, 2013 [7]). Tuy nhiên, ORD không phải là một biến quan trắc, do đó không có chuỗi số liệu lịch sử. Thông thường $\mathrm{ORD}$ được xác định thông qua chuỗi số liệu mưa ngày dựa trên các chỉ tiêu nào đó. Trong phạm vi bài báo này, các chỉ tiêu sau đây sẽ được sử dụng.

1) Chỉ tiêu S-S (Stern và CS, 1981 [17]). Đồng thời thoả mãn các điều kiện sau đây:

- Tổng lượng mưa 5 ngày liên tiếp phải lớn hơn $25 \mathrm{~mm}$;

- Ngày bắt đầu và ít nhất 2 trong 5 ngày liên tiếp phải đạt lượng mưa ngày trên $0.1 \mathrm{~mm} /$ ngày;

- Trong 30 ngày tiếp theo kể từ ngày bắt đầu không có quá 7 ngày liên tiếp không mưa.

2) Chỉ tiêu S-S1 (là biến thể của chỉ tiêu S$\mathrm{S})$. Trên cơ sở xem xét điều kiện thực tế ở Tây Nguyên, chỉ tiêu S-S1 được chúng tôi đưa ra khi bổ sung thêm một điều kiện sau:

- Trên $50 \%$ số trạm trong vùng thỏa mãn ngày bắt đầu mùa mưa đã được xác định theo $\mathrm{S}-\mathrm{S}$ có lượng mưa trên $0.1 \mathrm{~mm} / \mathrm{ngày}$.

3) Chỉ tiêu S-Z (Zhang và CS, 2002 [8]). Trước khi áp dụng chỉ tiêu này, chuỗi số liệu lượng mưa trạm phải được làm trơn bằng phương pháp trung bình trượt với bước trượt 5 
ngày. Trên cơ sở chuỗi số liệu mới này, ngày bắt đầu phải thoả mãn đồng thời các điều kiện sau:

- 5 ngày liên tiếp kể từ ngày bắt đầu phải có lượng mưa trên $5 \mathrm{~mm} /$ ngày;

- Trong vòng 20 ngày tiếp theo kể từ ngày bắt đầu ít nhất phải có 10 ngày có lượng mưa 5 $\mathrm{mm} /$ ngày

4) Chỉ tiêu S-VN. Chỉ tiêu này được chúng tôi đề xuất như là một thử nghiệm dựa trên điều kiện thực tế của Việt Nam, trong đó ngày bắt đầu mùa mưa phải đồng thời thoả mãn các điều kiện:

- Tổng lượng mưa 5 ngày liên tiếp phải lớn hơn hoặc bằng $20 \mathrm{~mm}$ và phải kéo dài liên tục cho 10 ngày tiếp theo;

- Phải có ít nhất $50 \%$ số trạm trong vùng thoả mãn điều kiện trên đây.

\section{3. Đánh giá xu thế biến đổi của ngày bắt đầu mùa mura}

Việc đánh giá xu thế biến đổi của các yếu tố và hiện tượng khí tượng thuỷ văn đã được đề cập đến trong nhiều công trình nghiên cứu trước đây. Thông thường có hai cách tiếp cận là phương pháp tham số và phương pháp phi tham số. Phương pháp tham số đánh giá xu thế biến đổi tuyến tính của một biến dựa trên dấu và độ lớn của hệ số góc $\mathrm{a}_{1}$ của phương trình hồi qui $\mathrm{y}$ $=\mathrm{a}_{\mathrm{o}}+\mathrm{a}_{1} \mathrm{t}$, trong đó $\mathrm{y}$ là biến được xem xét, $\mathrm{t}$ là thời gian (năm), còn $\mathrm{a}_{\mathrm{o}}$ là hệ số tự do. Phương pháp phi tham số thường dựa vào hệ số góc Sen (Sen, 1968 [18]) và kiểm nghiệm xu thế MannKendall. Chi tiết về phương pháp này có thể xem, chẳng hạn tại Kendall và CS (1975) [19]. Việc xác định xu thế biến đổi của ORD cho khu vực Tây Nguyên trong nghiên cứu này được thực hiện tương tự như Ngô Đức Thành và CS (2012) [20].

\subsection{Xây dưng phương trình dụ báo ORD}

Đánh giá khả năng dự báo hạn mùa ORD cho khu vực Tây Nguyên từ sản phẩm mô hình số là một trong những mục tiêu chính của nghiên cứu này. Do ORD không phải là sản phẩm dự báo của mô hình nên bài toán dẫn đến việc xây dựng phương trình mô tả mối liên hệ giữa yếu tố dự báo ORD và các biến đầu ra của mô hình có thể làm nhân tố dự báo. Các nhân tố dự báo được lựa chọn dựa trên mối quan hệ tương quan giữa $\mathrm{ORD}$ và các trường qui mô lớn. Như là thử nghiệm đầu tiên, trong nghiên cứu này chúng tôi chọn ba trường là $\mathrm{PMSL}$, U850 và $S S T$ từ số liệu CFSR0.5 của các tháng 1-4. Trên cơ sở đó, bằng phương pháp phân tích thành phần chính, các nhân tố dự tuyển sẽ được xác định. Phương trình dự báo cuối cùng sẽ được xây dựng bằng phương pháp hồi qui từng bước trong đó các nhân tố dự báo sẽ được tuyển chọn từ bộ nhân tố dự tuyển.

Bảng 1. Danh sách và toạ độ các trạm khí tượng được sử dụng số liệu

\begin{tabular}{llllllll}
\hline STT & Tên trạm & Kinh độ & Vĩ độ & STT & Tên trạm & Kinh độ & Vĩ độ \\
\hline 1 & Đăk Tô & 107.83 & 14.65 & 6 & $\begin{array}{l}\text { Buôn Ma } \\
\text { Thuột }\end{array}$ & 108.05 & 12.67 \\
2 & Kon Tum & 108.00 & 14.33 & 7 & Đăk Nông & 107.68 & 12.00 \\
3 & Pleiku & 108.02 & 13.97 & 8 & Đà Lạt & 108.45 & 11.95 \\
4 & Buôn Hồ & 108.27 & 12.92 & 9 & Liên & 108.38 & 11.75 \\
5 & Eakmat & 108.13 & 12.68 & 10 & Bhương & 107.82 & 11.53 \\
\hline
\end{tabular}


Bảng 2. Ngày bắt đầu mùa mưa trên khu vực Tây Nguyên xác định theo các chỉ tiêu khác nhau

\begin{tabular}{llllllllll}
\hline Năm & S-S & S-S1 & S-Z & S-VN & Năm & S-S & S-S1 & S-Z & S-VN \\
\hline 1981 & $7-5$ & $8-5$ & $18-4$ & $14-4$ & 1997 & $19-4$ & $19-4$ & $10-4$ & $4-4$ \\
1982 & $11-5$ & $12-5$ & $29-4$ & $22-4$ & 1998 & $14-5$ & $14-5$ & $8-5$ & $11-4$ \\
1983 & $15-5$ & $15-5$ & $11-5$ & $5-5$ & 1999 & $2-4$ & $3-4$ & $21--3$ & $26-3$ \\
1984 & $16-4$ & $16-4$ & $18-4$ & $12-4$ & 2000 & $5-4$ & $9-4$ & $26--3$ & $9-4$ \\
1985 & $17-4$ & $18-4$ & $21-4$ & $19-4$ & 2001 & $22-4$ & $24-4$ & $12-4$ & $23-3$ \\
1986 & $4-5$ & $7-5$ & $22-4$ & $1-5$ & 2002 & $10-5$ & $11-5$ & $19-4$ & $2-5$ \\
1987 & $17-5$ & $19-5$ & $12-5$ & $2-5$ & 2003 & $26-4$ & $4-5$ & $29-4$ & $29-4$ \\
1988 & $23-4$ & $7-5$ & $13-4$ & $25-4$ & 2004 & $19-4$ & $20-4$ & $20-4$ & $4-5$ \\
1989 & $15-4$ & $16-4$ & $23-3$ & $14-3$ & 2005 & $3-5$ & $4-5$ & $8-5$ & $4-5$ \\
1990 & $18-4$ & $27-4$ & $20-4$ & $30-4$ & 2006 & $18-5$ & $19-5$ & $4-4$ & $5-4$ \\
1991 & $15-5$ & $23-5$ & $11-5$ & $28-4$ & 2007 & $15-4$ & $20-4$ & $19-4$ & $1-5$ \\
1992 & $24-4$ & $26-4$ & $29-4$ & $8-4$ & 2008 & $20-4$ & $21-4$ & $1-4$ & $27-4$ \\
1993 & $29-4$ & $30-4$ & $8-5$ & $6-5$ & 2009 & $11-4$ & $11-4$ & $14-4$ & $11-4$ \\
1994 & $20-4$ & $25-4$ & $12-4$ & $5-4$ & 2010 & $4-5$ & $15-5$ & $26-4$ & $28-4$ \\
1995 & $23-4$ & $6-5$ & $3-5$ & $5-5$ & T.Bình & $26-4$ & $29-4$ & $19-4$ & $18-4$ \\
1996 & $26-4$ & $27-4$ & $15-4$ & $30--3$ & ĐLC & 13 & 13 & 15 & 15 \\
\hline
\end{tabular}

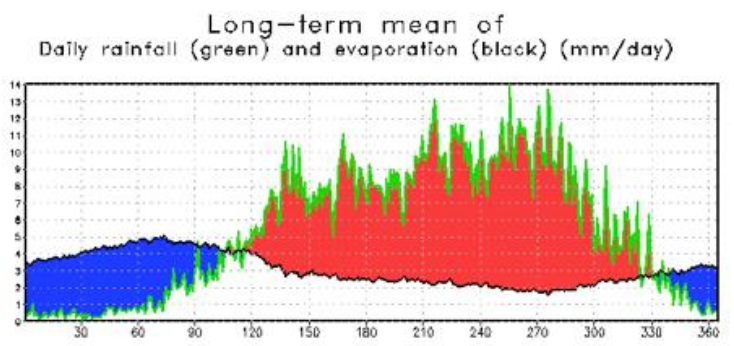

Hình 1. Trung bình nhiều năm của lượng mưa và lượng bốc hơi ngày ở Tây Nguyên.

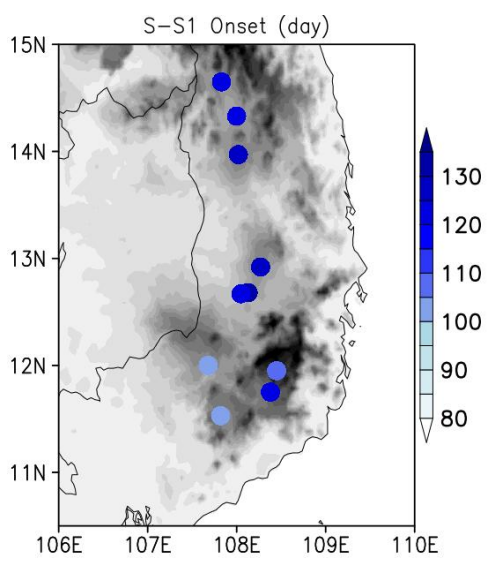

Hình 2. Phân bố ORD trung bình giai đoạn 1981-2010 ở Tây Nguyên. Thang màu chỉ số thứ tự ngày trong năm, từ $1 / 1$ đến $31 / 12$.

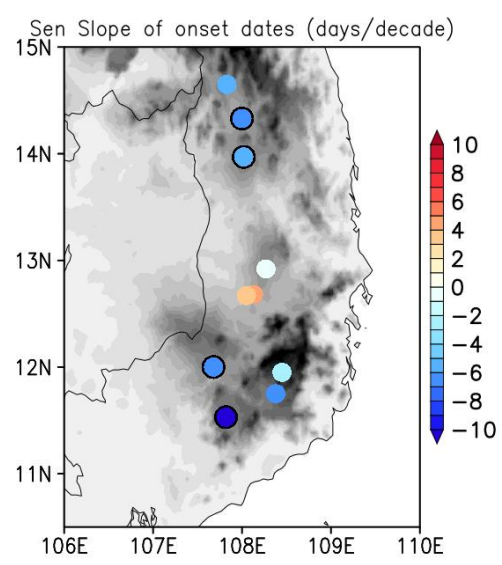

Hình 3. Xu thế biến đổi của ORD ở Tây Nguyên (ngày/thập kỷ). 


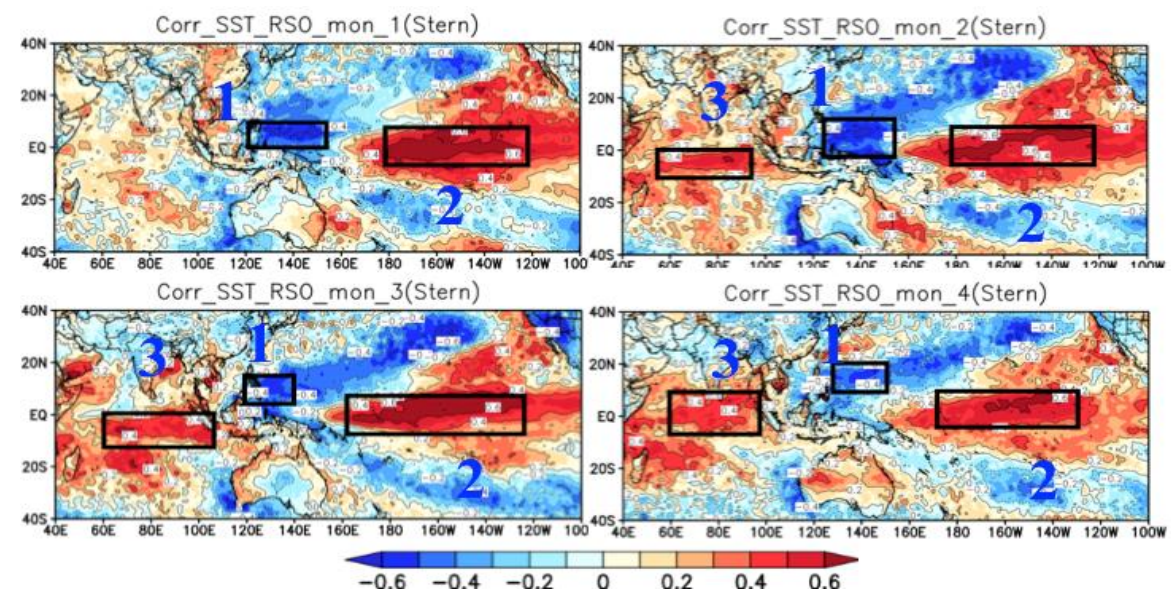

Hình 4. Hệ số tương quan giữa ORD ở Tây Nguyên và nhiệt độ mặt nước biển (SST) các tháng 1-4.

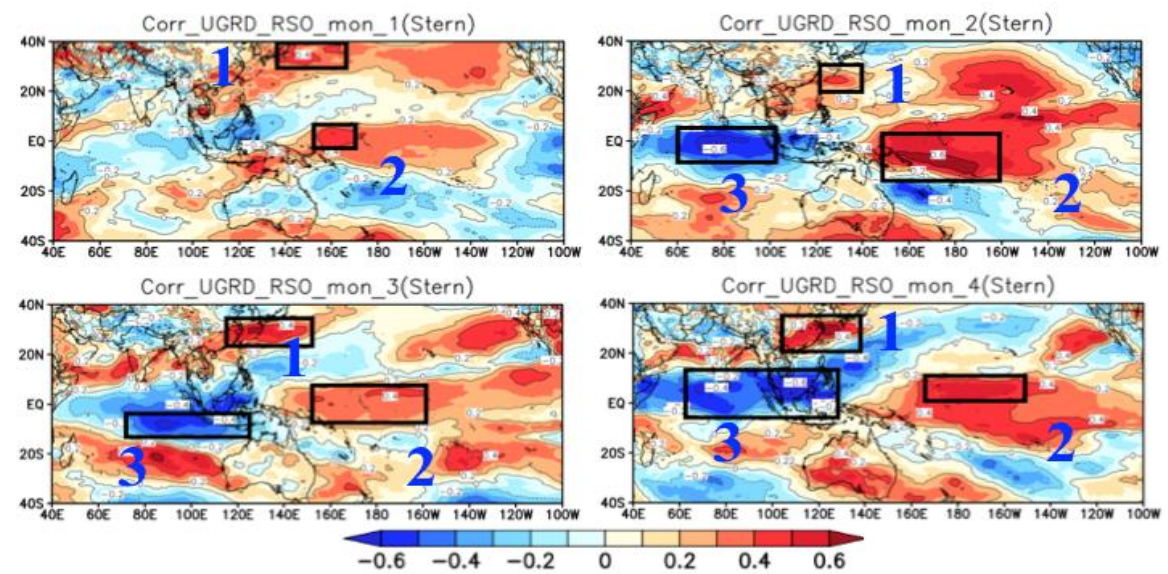

Hình 5. Hệ số tương quan giữa ORD và gió vĩ hướng mực $850 \mathrm{mb}$ (U850) các tháng 1-4.

\section{Kết quả và thảo luận}

\subsection{Ngày bắt đầu mùa muxa ở Tây Nguyên và xu thế biến đổi}

Bảng 2 dẫn ra kết quả xác định ngày bắt đầu mùa mưa trung bình cho toàn khu vực Tây Nguyên giai đoạn 1981-2010 theo 4 chỉ tiêu nêu ra ở mục 2.2. Có thể nhận thấy rằng, các chỉ tiêu khác nhau cho ước lượng ORD khác nhau khá nhiều. Theo chỉ tiêu S-S, ORD trung bình vào ngày $26 / 4$ với mức dao động trung bình (độ lệch chuẩn) 13 ngày, sớm nhất vào ngày $2 / 4$ (1999) và muộn nhất là $18 / 5$ (2006). Như vậy biên độ dao động cực đại của ORD tính theo S-S là 47 ngày (một tháng rưỡi). Khi đưa thêm điều kiện về phân bố mưa theo không gian vào $\mathrm{S}-\mathrm{S}$ để nhận được chỉ tiêu $\mathrm{S}-\mathrm{S} 1$, độ lệch chuẩn của ORD không thay đổi nhưng ORD xảy ra muộn hơn một chút, trung bình là 29/4, sớm nhất vào $3 / 4$ (1999) và muộn nhất vào 23/5 (1991). Như vậy, sự ràng buộc chặt chẽ hơn của $\mathrm{S}-\mathrm{S} 1$ so với $\mathrm{S}-\mathrm{S}$ đã làm tăng biên độ dao động cực đại của ORD (51 ngày). Cũng với điều kiện về phân bố mưa theo không gian như S-S1 nhưng S-VN cho kết quả ORD xảy ra sớm hơn rất nhiều, trung bình vào ngày $18 / 4$, sớm nhất vào $14 / 3$ (1989), muộn nhất là $5 / 5$ (1983). Kết quả xác định ORD theo S-Z cũng gần tương tự như $\mathrm{S}-\mathrm{VN}$ (xem bảng 2).

Theo Pham Xuan Thanh và CS (2010) [21], ngày bắt đầu gió mùa mùa hè ở Nam Bộ trung 
bình là 12/5. Nếu coi ngày bắt đầu gió mùa mùa hè ở Tây Nguyên và Nam Bộ là như nhau thì ngày bắt đầu mùa mưa ở Tây Nguyên đến sớm hơn khoảng 2-3 tuần. Trong 4 chỉ tiêu, $S-Z$ và $\mathrm{S}-\mathrm{VN}$ cho $\mathrm{ORD}$ vào khoảng giữa tháng 4 , trong khi $Z-S$ và $S-S 1$ cho $O R D$ vào cuối tháng 4 . Từ trung bình nhiều năm của biến trình năm của lượng mưa và lượng bốc hơi ngày được cho trên hình 1 có thể cho rằng mùa mưa ở Tây Nguyên bắt đầu vào khoảng cuối tháng 4 đầu tháng 5. Qua đó có thể thấy kết quả xác định ORD theo S-S1 là hợp lý hơn cả. Do đó, trong bài này $\mathrm{ORD}$ xác định theo $\mathrm{S}-\mathrm{S} 1$ sẽ được sử dụng cho những phân tích, đánh giá tiếp theo.

Giá trị trung bình nhiều năm của $\mathrm{ORD}$ xác định theo S-S1 cho các trạm trên khu vực Tây Nguyên được trình bày trên hình 2. Qua đó thấy rằng, mùa mưa ở Tây Nguyên không xảy ra đồng thời trên toàn khu vực. Mùa mưa đến sớm nhất ở phía nam (Lâm Đồng - Đăk Nông), khoảng giữa tháng 4 , sau đó đến phía bắc (Kon Tum - Pleiku), khoảng cuối tháng 4 , và muộn nhất ở khu vực miền trung (Buôn Ma Thuột) khoảng giữa tháng 5 . Nguyên nhân của sự xuất hiện mùa mưa khác nhau giữa các vùng có thể là do nhân tố địa hình. Mùa mưa ở Tây Nguyên có xu thế đến sớm hơn ở phía nam và phía bắc, trung bình khoảng 5-7 ngày/thập kỷ, và hầu như không đổi ở khu vực miền trung (hình 3 ). Xu thế mùa mưa bắt đầu sớm hơn ở Tây Nguyên có thể là một dấu hiệu tốt vì nhờ đó tính khắc nghiệt do khô hạn, thiếu nước của những ngày cuối mùa khô có xu hướng kết thúc sớm hơn.

\subsection{Tính dụ báo được của ngày bắt đầu mùa mưa}

Trên cơ sở kết quả phân tích mối quan hệ thống kê giữa $\mathrm{ORD}$ và các trường $\mathrm{SST}, \mathrm{U} 850$ và PMSL, một số khu vực đã được lựa chọn (các hình 4-6) để tiến hành phân tích thành phần chính nhằm tạo ra các nhân tố dự tuyển cho việc xây dựng phương trình dự báo. Kết quả phân tích thành phần chính (không trình bày ở đây) cho thấy đa số các trường hợp lượng thông tin đóng góp của thành phần chính thứ nhất đã đạt đến $70-80 \%$, thậm chí một số trường hợp đạt gần $90 \%$. Khi lấy đến thành phần chính thứ ba, hầu hết các trường hợp đều mô tả được trên dưới $90 \%$ phương sai tổng cộng. Điều đó nói lên rằng các thành phần chính được sử dụng làm các nhân tố dự tuyển đã có thể phản ánh khá đầy đủ thông tin của các biến trường $\mathrm{SST}$, U850 và PMSL tại các vùng được chọn. Tuy nhiên, để đảm bảo sự cân đối giữa số biến dự tuyển và độ dài chuỗi thời gian, chỉ có một số thành phần chính đầu tiên được sử dụng tuỳ thuộc vào mức độ đóng góp chung của chúng.

Các nhân tố dự tuyển được sử dụng như những nhân tố dự báo ban đầu sẽ được tuyển chọn thông qua thủ tục hồi qui từng bước. Kết quả nhận được phương trình dự báo cuối cùng trong đó ORD là yếu tố dự báo, nhân tố dự báo và các hệ số hồi qui tương ứng của phương trình dự báo được cho trong bảng 3 . Từ đó có thể thấy SST_A1 và PMSL_A1 càng lớn thì ORD càng xảy ra sớm; mặt khác, nếu gió đông tháng 3 của U850 A3 (tương ứng với xoáy nghịch Nam bán cầu khu vực Ấn Độ dương xích đạo) và gió tây tháng 2 của U850 A2 (dòng vượt xích đạo nam Thái Bình dương) càng lớn thì $O R D$ cũng xảy ra sớm hơn. Mặc dù vậy, vì giá trị của hệ số tự do trong phương trình hồi qui tương đương với ORD trung bình ( ngày thứ 120 , tức $30 / 4$ ) nên đóng góp của các nhân tố dự báo ở đây hầu như chỉ mang ý nghĩa điều chỉnh giá trị ORD.

Hình 8 dẫn ra kết quả dự báo ORD theo phương trình hồi qui trong bảng 3 và $O R D$ xác định theo S-S1 (bảng 2) như là số liệu quan trắc. Một cách định tính có thể nói kết quả dự báo ORD khá gần với thực tế. Tuy nhiên để đánh giá một cách định lượng, chúng tôi đã tính sai số trung bình (ME) và sai số trung bình tuyệt đối MAE đồng thời xác định phân bố tần suất của sai số (dự báo trừ đi quan trắc) (hình 9). Kết quả nhận được là $\mathrm{ME}=0.2$ (ngày) và $\mathrm{MAE}=6$ (ngày). Giá trị sai số có tần suất cao nhất là 3 ngày (khoảng $30 \%$ ), sau đó là -3 ngày và 6 ngày (khoảng $17 \%$ cho mỗi giá trị sai số) (hình 9). Như vậy, phương trình dự báo có thiên hướng dự báo ORD muộn hơn một chút so với thực tế. Sai số dự báo ORD vào khoảng một tuần. 


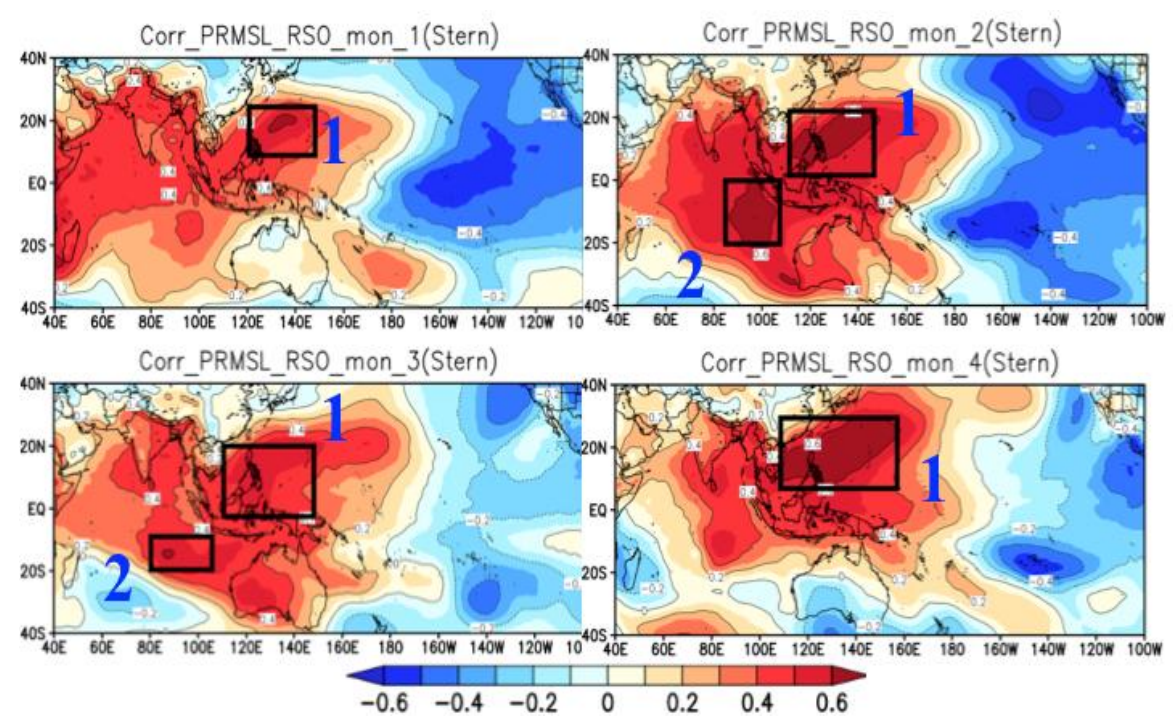

Hình 6. Hệ số tương quan giữa ORD và khí áp mực biển trung bình (PMSL) các tháng 1-4.

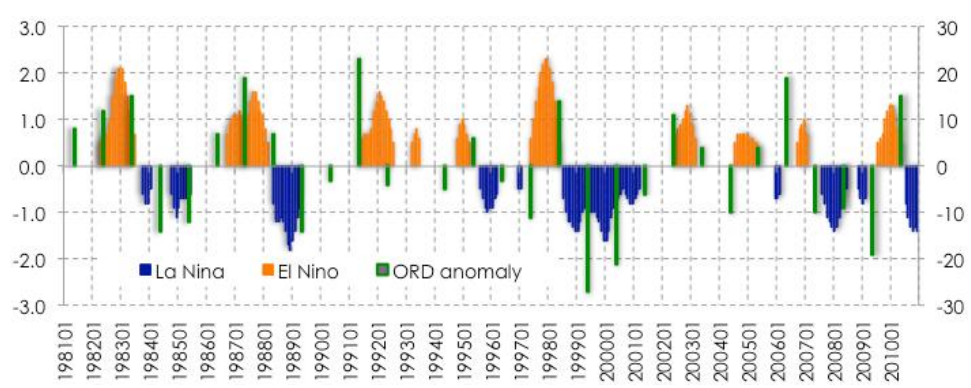

Hình 7. Quan hệ giữa ngày bắt đầu mùa mưa ở Tây Nguyên và ENSO.

Bảng 3. Danh sách các nhân tố dự báo và các hệ số hồi qui tương ứng của phương trình dự báo ORD cho khu vực Tây Nguyên. Trong tên các nhân tố dự báo, hai nhóm ký hiệu đầu có ý nghĩa như trong mục 3.2 , nhóm thứ ba là tháng và nhóm thứ tư là số thứ tự thành phần chính được chọn

\begin{tabular}{llll}
\hline Tên nhân tố dự báo & Hệ số hồi qui & Tên nhân tố dự báo & Hệ số hồi qui \\
\hline SST_A1_Jan_1 & -32.050 & U850_A3_Mar_3 & 22.747 \\
U850_A2_Feb_2 & -17.615 & PMSL_A1_Apr_1 & 34.316 \\
SST_A1_Mar_3 & -19.484 & Hệ số tự do & 119.867 \\
\hline
\end{tabular}




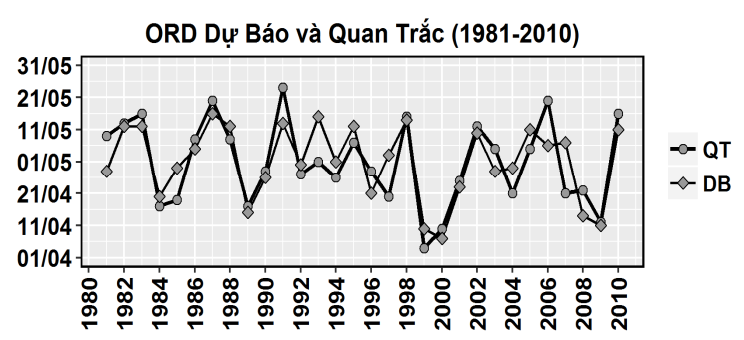

Hình 8. So sánh ORD dự báo và quan trắc.

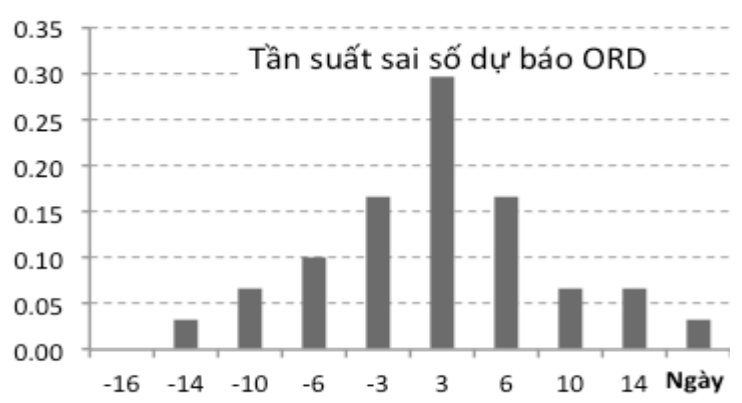

Hình 9. Tần suất của sai số dự báo.

\section{Kết luận}

Trong nghiên cứu này, sử dụng các chuỗi số liệu lượng mưa ngày thời kỳ 1981-2010 từ 10 trạm quan trắc khí tượng trên khu vực Tây Nguyên, chúng tôi đã tiến hành xác định ngày bắt đầu mùa mưa theo 4 chỉ tiêu khác nhau, đồng thời khảo sát xu thế biến đổi cũng như tính dự báo được của ngày bắt đầu mùa mưa (ORD) ở đây. Kết quả nhận được cho phép rút ra một số nhận xét sau:

1) ORD tính theo các chỉ tiêu khác nhau chênh lệch nhau khá lớn. Trong bốn chỉ tiêu được khảo sát, hai chỉ tiêu $S-Z$ và $Z-V N$ cho kết quả gần tương đương nhau với ORD sớm hơn hai chỉ tiêu $\mathrm{S}-\mathrm{S} 1$ và $\mathrm{S}-\mathrm{S}$. ORD tính theo hai chỉ tiêu $\mathrm{S}-\mathrm{S} 1$ và $\mathrm{S}-\mathrm{S}$ dường như phù hợp với thực tế hơn khi so sánh biến trình năm của lượng mưa và lượng bốc hơi ngày. Sự điều chỉnh $\mathrm{S}-\mathrm{S}$ thành S-S1 tạo ra mối ràng buộc chặt hơn về phân bố không gian nên cho kết quả sát hơn với thực tế. Mặc dù vậy, có lẽ cần có những khảo sát sâu hơn để đảm bảo tính chắc chắn của các chỉ tiêu sẽ được áp dụng.
2) Ngày bắt đầu mùa mưa ở Tây Nguyên không diễn ra đồng thời trên toàn khu vực mà thường đến sớm hơn ở phía nam, sau đó đến phía bắc và muộn nhất ở vùng trung Tây Nguyên (Buôn Ma Thuột). Chênh lệch của ORD giữa các vùng vào khoảng một tuần. $\mathrm{ORD}$ ở phía nam và phía bắc Tây Nguyên có xu thế đến sớm hơn, khoảng 5-7 ngày/thập kỷ, trong khi ở miền trung gần như không có xu thế.

3) Quan hệ tương quan giữa ORD ở Tây Nguyên và $\mathrm{SST}$, U850 và PMSL ở một số trung tâm khá cao. Sự biến thiên của $\mathrm{SST}$, U850 và PMSL ở các trung tâm này có thể là là những nhân tố chi phối các quá trình nhiệt động lực khí quyển liên quan đến sự mở đầu mùa mưa ở Tây Nguyên. Tuy nhiên, để có thể lý giải đầy đủ vấn đề này cần thiết phải có những nghiên cứu, khảo sát sâu hơn.

4) Việc sử dụng phân tích thành phần chính các trường SST, U850 và PMSL làm nhân tố dự báo ban đầu kết hợp với thủ tục lọc nhân tố bằng phương pháp hồi qui từng bước để xây dựng phương trình dự báo ORD cho Tây Nguyên và kết quả đánh giá sai số cho phép nhận định rằng vấn đề dự báo $\mathrm{ORD}$ là hoàn toàn có thể thực hiện được. Sai số dự báo ORD khá nhỏ và không biến động nhiều. Trong tương lai, việc sử dụng sản phẩm dự báo của mô hình số làm nhân tố dự báo để dự báo hạn mùa ORD cho Tây Nguyên là hoàn toàn khả thi.

\section{Lời cảm ơn}

Bài báo được thực hiện và hoàn thành với sự hỗ trợ của đề tài NAFOSTED mã số 105.062014.44 cũng như của "Sáng kiến Cà phê \& Khí hậu (Coffee \&Climate Initiative) - Embden Drishaus \& Epping Consulting $\mathrm{GmbH}$ Vietnam".

\section{Tài liệu tham khảo}

[1] Matsumoto J., 1997: Seasonal Transition of Summer Rainy Season over Indochina and 
Adjacent Monsoon Region. J.Adv.Atmos.Sci, 14(2): 231. doi: 10.1007/s00367-997-0022-0.

[2] Ngo-Duc T., J. Matsumoto, H. Kamimera, and H.H. Bui, 2013: Monthly adjustment of Global Satellite Mapping of Precipitation (GS Ma P) data over the Vu Gia-Thu Bon River Basin in Central Vietnam using an artificial neural network. Hydrological Research Letters, 7(4), 85-90. doi: $10.3178 / \mathrm{hrl} .7 .85$.

[3] Nguyen-Le Dzung, Jun Matsumoto, Thanh NgoDuc, 2015a: Onset of the Rainy Seasons in the Eastern Indochina Peninsula. J. Clim, Vol. 28, p5645-5666.

[4] Nguyen-Le Dzung and Jun Matsumoto, 2015b: Delayed withdrawal of the autumn rainy season over central Vietnam in recent decades. Int. J. Climatol. Published online in Wiley Online Library, doi: 10.1002/joc.4533

[5] Nguyen-Thi, H. A., J. Matsumoto, T. Ngo-Duc, and N. Endo, 2012: A Climatological Study of Tropical Cyclone Rainfall in Vietnam. SOLA, 8, 041-044, doi: 10.2151/sola.2012-011.

[6] Yen Ming-Cheng, Tsing-Chang Chen, Hao-Lin $\mathrm{Hu}$, Ren-Yow Tzeng, Dinh Duc Tu, Nguyen Thi Tan Thanh, Chow Jeng Wong, 2011: Interannual Variation of the Fall Rainfall in Central Vietnam. Journal of the Meteorological Society of Japan, Vol. 89A, pp. 259-270, doi:10.2151/jmsj.2011-A16.

[7] Nguyễn Đức Ngữ và Nguyễn Trọng Hiệu, 2013: Khí hậu và tài nguyên khí hậu Việt Nam. NXB Khoa học và Kỹ thuật, Hà Nội, 296 trang.

[8] Zhang Y., Li T., Wang B. and et.al., 2002: Onset of the summer monsoon over the Indochina Peninsula: Climatology and interannual variations. Int. J. Climatol., 15(22), 3206-3221.

[9] Laux, P., Kunstmann, H. and Bárdossy, A., 2008: Predicting the regional onset of the rainy season in West Africa. Int. J. Climatol., 28: 329-342. doi:10.1002/joc. 1542 .

[10] Wang, B. and LinHo., 2002: Rainy Season of the Asian - Pacific Summer Monsoon. Int. J. Climatol., 15, 386-398.

[11] Lau K.M. và Yang S., 1997: Climatology and interannual variability of the southeast asian summer monsoon. Adv Atmos Sci, 14(2), 141-162.
[12] Zhou Wen and Johnny C. L. Chan, 2007: ENSO and the South China Sea summer monsoon onset. Int. J. Climatol. 27: 157-167.

[13] Nguyễn Thi Hiền Thuận, Chiêu Kim Quỳnh, 2007: Nhận xét về sự biến động của các đặc trưng gió mùa mùa hè ở khu vực Nam Bộ trong các năm ENSO. Tuyển tập báo cáo Hội nghị khoa học lần thứ 10, Viện KH KTTV và MT, 314-322.

[14] Nguyen, T. D., Uvo, C. and Rosbjerg, D., 2007: Relationship between the tropical Pacific and Indian Ocean sea-surface temperature and monthly precipitation over the central highlands, Vietnam. Int. J. Climatol., 27: 1439-1454. doi:10.1002/joc. 1486 .

[15] Moron V., Robertson A.W., và Boer R., 2009: Spatial coherence and seasonal predictability of monsoon onset over Indonesia. Int. J. Climatol., 22(3), 840-850.

[16] Phan Van Tan, Ngo Duc Thanh and Nguyen Van Hiep, 2013: A review of evidence of recent climate change in the Central Highlands of Vietnam. Produced for the initiative for coffee \& climate, http://www.coffeeandclimate.org

[17] Stern RD, Dennett MD, Garbutt DJ., 1981: The start of the rains in West Africa. Journal of Climatology 1: 59-68

[18] Sen, P.K., 1968: Estimates of the Regression Coefficient Based on Kendall's Tau. Journal of the American Statistical Association, 63(324) (1968) 1379-1389.

[19] Kendall, M.G., 1975: Rank Correlation Methods. Charles Griffin, London, 272 pp, 1975.

[20] Ngô Đức Thành, Phan Văn Tân, 2012: Kiểm nghiệm phi tham số xu thế biến đổi của một số yểu tố khí tượng cho giai đoạn 1961-2007. Tạp chí khoa học, ĐHQGHN, Khoa học Tự nhiên và Công nghệ, Tập 28, số 3S, tr.129 -135

[21] Pham Xuan Thanh, Bernard Fontaine, Nathalie Philippon, 2010: Onset of the summer monsoon over the southern Vietnam and its predictability. Theor Appl Climatol (2010) 99:105-113 doi 10.1007/s00704-009-0115-z. 


\title{
Change in Onset Date of Rainy Season in Central Highlands and Predictability
}

\author{
Phan Van Tan ${ }^{1}$, Pham Thanh $\mathrm{Ha}^{1}$, Nguyen Dang Quang ${ }^{2}$, \\ Nguyen Van Hiep ${ }^{3}$, Ngo Duc Thanh ${ }^{4}$ \\ ${ }^{1}$ VNU University of Science, 334 Nguyen Trai, Hanoi, Vietnam \\ ${ }^{2}$ National Center for Hodro-Meteorology \\ ${ }^{3}$ Institute of Geophysics, Vietnam Academy of Science and Technology \\ ${ }^{4}$ University of Science and Technology of Hanoi, Vietnam Academy of Science and Technology
}

\begin{abstract}
Using observed daily rainfall data from meteorological stations in Central Highlands $(\mathrm{CH})$, Vietnam during the period 1981-2010, some rainfall characteristics including rainy season onset date (ORD), its trend of change as well as its predictability were investigated. The obtained results showed that: 1) The ORD in $\mathrm{CH}$ varies widely from year to year. Spatially, the onset firstly starts at the south $\mathrm{CH}$, then spreads to the north $\mathrm{CH}$ and latest at mid $\mathrm{CH}$. The rainy season in $\mathrm{CH}$ generally starts in between mid April to mid May with an average of about $30^{\text {th }}$ April. There are signals indicating that the ORD in CH is later in El Niño years and earlier in La Niña years; 2) The rainy season in $\mathrm{CH}$ tends to start earlier at about 5-7 days/decade; 3) The ORD in $\mathrm{CH}$ has a high positive correlation with sea surface temperature (SST) over the equatorial central Pacific and the equatorial Indian ocean, with $850 \mathrm{hPa}$ (U850) zonal wind over the equatorial central and northwest Pacific, and with mean sea level pressure (PMSL) over the west Pacific and Indian Ocean. The ORD however has a negative correlation with SST over the equatorial west Pacific and with U850 over the Southeast Asia maritime region and the equatorial Indian Ocean. In addition, the principle component analysis (PCA) was applied to SST, U850 and PMSL over the selected areas to create a set of predictors, and then the stepwise regression method was used to build an ORD prediction equation for $\mathrm{CH}$. Results showed that mean error of the method is 0,2 day, and the absolute mean error is 6 days.
\end{abstract}

Keywords: Rainy season onset date, Rainfall forecast, Central Highlands, Vietnam. 